\title{
The Paperless Lab - Streamlining a Modern Unit Operations Laboratory Course to Reduce Faculty Time Commitment
}

\section{Dr. Matthew Cooper, North Carolina State University}

Dr. Matthew Cooper is a Teaching Assistant Professor in the Department of Chemical and Biomolecular Engineering at North Carolina State University. He was born in Elkins, W.Va. and received his B.S. in Chemical Engineering from West Virginia University. Following a position as an oilfield engineer with Schlumberger, Dr. Cooper received his MS and Ph.D. in Chemical Engineering from Ohio University. Upon completion of graduate studies in 2008, Dr. Cooper moved to the Raleigh, NC area to serve as a research chemical engineer for RTI International, focusing on the development of novel technologies for the energy sector. Dr. Cooper joined the Department of Chemical and Biomolecular Engineering at North Carolina State University in 2011, where he currently teaches the Unit Operations I and II laboratory sequence, Material and Energy Balances, Transport Phenomena and Mathematical / Computational Methods. He is the recipient of the 2014 NCSU Outstanding Teacher Award and the 2014 ASEE Southeastern Section Outstanding New Teacher Award, as well as the 2013 Joseph J. Martin Award from the ASEE Chemical Engineering Division; he also currently serves as the ASEE ChE division's newsletter editor. Dr. Cooper's research interests include effective teaching, conceptual and inductive learning, integrating writing and speaking into the curriculum, and professional ethics. 


\section{The Paperless Lab - Streamlining a Modern Unit Operations Laboratory Course to Reduce Faculty Time Commitment}

\section{Introduction}

Unit Operations (UO) laboratory courses are important, required offerings in chemical engineering curricula due to the similarities of required laboratory tasks to those relevant in industry, including start-up, steady-state operation, shut down, data collection and analysis, and written/oral communication. Students are typically placed into engineering teams when completing UO laboratory tasks; this echoes the modern workplace which relies on engineering teams to address complex problems beyond the scope and abilities of a single person ${ }^{1-3}$.

The use of student teams in UO courses offers ample opportunity for cooperative learning, defined as "an instructional paradigm in which teams of students work on structured tasks under conditions that meet five criteria: positive interdependence, individual accountability, face-toface interaction, appropriate use of collaborative skills, and regular self-assessment of team functioning"4. Taking advantage of opportunities for cooperative learning is important since students who participate achieve greater confidence and conceptual understanding ${ }^{5,6}$. Without appropriate cooperative training, students can graduate without the teamwork and leadership skills necessary for success in their industrial careers ${ }^{5-8}$. Dysfunction encountered by student groups during their work represents a critical real-life problem they must solve by devising and implementing corrective action appropriately ${ }^{5,9-11}$. It has also been shown that students must learn teamwork strategies by "doing" - skills developed through cooperative learning cannot be acquired via lectures, workshops, etc. $5,9,12,13$ A key to student growth via cooperative learning is the guidance and arbitration of a helpful instructor ${ }^{4,14-16}$.

Despite the importance of UO courses in chemical engineering programs, many faculty members avoid opportunities to teach them. Myriad time-consuming and (at times) frustrating tasks are required of the UO instructor, including assigning student teams, preparing students for laboratories, grading reports, and assessing peer evaluation results. Since faculty are often busy with other commitments such as research, grant writing, student advising, etc., it is understandable that instructors feel they do not have the time available to do an excellent job teaching UO courses ${ }^{15,16}$.

Considering the importance of UO courses to the ChE curriculum, it would be ideal to relieve the pressure of time constraints upon instructors so that they can better manage their time while addressing available cooperative learning opportunities. With this in mind, this study describes the results of a number of approaches taken by the author to reduce time necessary to complete the more tedious tasks associated with instructing UO courses. The objective of this work is to inform the ChE faculty community of ways to reduce time spent teaching UO courses, while providing a critical look at the effectiveness of each tested method on the basis of time saved for the instructor, monetary cost to the department, and student participation and viewpoints. 
This study is planned to be completed across the Fall 2013 and Spring 2014 semesters; at the March 2014 conference proceedings submission deadline, only limited data was available for the Fall 2013 portion of the study. Additional data will be collected in Spring 2014 and presented at the 2014 ASEE Annual Conference.

\section{Methods}

A number of different course-streamlining options available to UO instructors were incorporated into two large ( 140 students total) junior and senior-level chemical engineering UO courses at the university level, namely:

- CATME - web-based assignment and evaluation of student teams using CATME.org ${ }^{17-19}$

- Paperless grading - digital submission, grading and feedback for laboratory reports using Turnitin.com

- Experiment preview videos - use of recordings of experiment preview lectures in place of in-person preview sessions ${ }^{20}$

- "Classroom Capture" - term referring to providing video and audio of lectures online for student review, a service offered at many universities

Each of these methods was evaluated during the Fall 2013 and Spring 2014 semesters. Data recorded for each method included:

- Amount of time the method saved for instructor

- Monetary cost for use of method

- Frequency students actually benefitted from method

- Open-ended student comments from end-of-semester course evaluations

\section{Results}

\subsection{CATME}

\subsubsection{Assigning student engineering teams}

Two of the many challenges of teaching UO courses are (1) initial assignment of student groups and (2) collecting peer evaluation data from student groups after each experiment to inform individual student grades. It has been shown that student engineering teams perform better and have improved attitudes when chosen by instructors rather than students, provided that the students in each group are heterogeneous in ability (as estimated by GPA) ${ }^{21-23}$. If students are required to meet outside of class (which is often the case for UO courses), it is also advised to assign students to teams with common blocks of available time ${ }^{14}$. In other words, to maximize student learning the UO instructor should ideally group students with dissimilar GPAs, but 
similar openings in their schedules - this task is arduous, tedious, and easy to overlook for a busy professor.

An instrument named the Comprehensive Assessment of Team Member Effectiveness (CATME) ${ }^{17-19}$ can be used to collect information from students prior to the semester, such as GPA and schedule, and then use this data to optimize the configurations of student teams using the criteria of dissimilar GPA and similar schedule. This process involves uploading a student course roster with accompanying email addresses to the CATME system, which then emails every student on the roster to request their individual GPA and schedule data. Teams can be optimized based on selected criteria with a click of a button. Assigning students teams using the criteria stated above without CATME is frustrating based on the personal experience of the author. Collecting necessary data involves an avalanche of student emails and distributing students into groups properly is not a straightforward exercise. Previous attempts to assign student teams by dissimilar GPA and similar schedule have taken 3-4 hours per semester when considering time spent emailing students, transcribing emailed student responses and determining teams.

As an aside, students can elect to not provide schedule and GPA data for use by CATME, but in practice this is atypical because non-responsive students only hurt themselves by possibly being placed in a group with students who do not share their open blocks of time. During the semesters observed $91 \%$ of students polled volunteered requested data to CATME.

\subsubsection{Collection of peer evaluation data}

Once students enter the industrial workforce or move on to graduate study, the ability to critically evaluate another person's work becomes essential ${ }^{24}$. With this in mind, a key component of cooperative learning is the evaluation of individual team member contributions ${ }^{14}$, 25,26 . Student evaluations can be collected in a number of ways, including via paper forms or $\mathrm{Wiki}^{24}$. However, from an instructor time-saving perspective it is desirable for student peer ratings to be automatically collected after each laboratory, and collated in a format which is easily transferable to a spreadsheet program for analysis.

Using CATME, surveys of student peer ratings can be automatically requested on specified dates and collected online. Data may then be cut-and-pasted into a spreadsheet. In previous semesters of the author's UO course peer evaluation data was collected using paper forms in class. In addition to consuming valuable class time and wasting paper, students anecdotally expressed apprehension over evaluating teammates who could be sitting next to them in class. Manually transcribing peer-evaluation scores into a spreadsheet from paper forms was onerous for the instructor. Total instructor time extracting necessary findings from paper peer-evaluation forms was 5-6 hours per semester. In contrast, setting up CATME to automatically collect and collate 
peer evaluation information for an entire semester takes less than one hour. During the semesters studied $93 \%$ of requests for peer evaluation scores via CATME were fulfilled by students, indicating students' comfort with the method.

\subsubsection{Student views and conclusion}

In order to probe student views on the instructor use of CATME to collect peer evaluation feedback, end-of-semester course evaluations included the question "In CHE 330/331, CATME is used to collect peer evaluation feedback digitally via the web. Would you prefer to fill out paper peer evaluation forms in class? Why?" Students gave uniformly positive feedback on providing peer evaluation feedback via CATME, as indicated by the following responses:

- "The CATME service is quick and efficient, and peer evaluation does not need to be done during class hours."

- “[Peer evaluations] are not worth wasting paper. Submitting it online also keeps it confidential."

- "I like the online version because then you do not have to be near your group members when it is being filled out. That allows me more freedom to put down what I actually think and allows me time to think over stuff instead of just writing based on whatever emotion I am feeling at the time of the class."

Based on student responses, students appreciated the privacy and outside-of-class nature of providing peer evaluation online via CATME. Additional student feedback on the assignment is planned to be collected in the Spring 2014 semester and presented at the 2014 ASEE Annual Conference.

Since CATME is free to use, allows grouping of students as suggested by literature, liked by students, and saves approximately $8-10$ hours of instructor time per semester, CATME is recommended for use by all UO instructors.

\subsection{Paperless laboratory report submission and grading}

Printing and transporting paper laboratory reports are sources of frustration for both UO instructors and students. Considering that a 100 student laboratory class will have $20-30$ student groups, report due dates often involve the instructor hauling dozens of sizable laboratory reports to and from classroom, office and home as part of the arduous grading process. Similarly, report printing is often a stressful time for students, who must endure printer problems, low print allowances and long queues, often at the last minute before a deadline. Paper laboratory reports present problems regarding paper waste, as well as the need to destroy graded reports.

Many universities use Turnitin.com for plagiarism screening of student papers ${ }^{27,28,29}$. As part of this service online grading tools are also available. An avenue is available for students to submit laboratory reports and for instructors to provide feedback electronically. In addition to solving 
many of the problems associated with grading hard copy reports, online grading can represent a needed change of pace for instructors with pain or dexterity issues in their wrists, hands, etc. which are aggravated by written grading. This paperless laboratory report submission and grading system was evaluated to determine if it a worthwhile endeavor for UO courses. Tablet computers have quickly grown in popularity in recent years, rising from an ownership rate of 3\% among US adults in 2011 to $34 \%$ in 2013 according to a Pew report ${ }^{30}$. A tablet computer was used by the instructor as the interface with Turnitin.com.

\subsubsection{Instructor experiences}

Reading text on a tablet computer is liked by some but frustrating for others, so instructors who prefer can use the paperless grading system via desktop or laptop. Grading UO reports using the tablet is somewhat more "clunky" and frustrating than using paper and pen. Highlighting text using a finger, then typing comments can require multiple tries, and entering technical comments which are quickly changed by the tablet's auto-correct function adds unnecessary frustration and time to grading. Anecdotally, it seems that digital grading on a tablet tended to encourage instructor comments based on content; highlighting, then marking small grammar or spelling errors was difficult and time consuming, so it was preferred to provide fewer, more detailed comments.

The amount of time spent grading reports electronically is described in Figure 1. It should be noted that though the subjects of each report are different, historically reports graded via hard copy have taken the author a similar amount of time to grade at 35 - 40 minutes. Based on Figure 1 , it appears that there may be a "learning curve" associated with using the paperless grading system: the first report graded using the system took more than an hour to complete, though by the end of the Fall 2013 semester grading time per report was reduced to approximately $35-45$ minutes, which is similar to the 35-40 minute period needed to grade a hard copy report. It is hypothesized that time spent by the instructor during paperless grading will continue to reduce as the instructor becomes more familiar with the grading software. This trend will be further studied in the Spring 2014 semester.

\subsubsection{Student views and conclusion}

Students were given the option to submit laboratory reports for grading either as a hard copy (as has traditionally been the case in the department's UO courses) or as a digital report. Over the Fall 2013 semester, most student groups chose to submit their reports for grading electronically, increasing from 6 out of 8 groups for the first round of reports to 7 out of 8 groups for each of the final two rounds of reports. These high levels of participation indicate that students view paperless report submission as a convenience. 


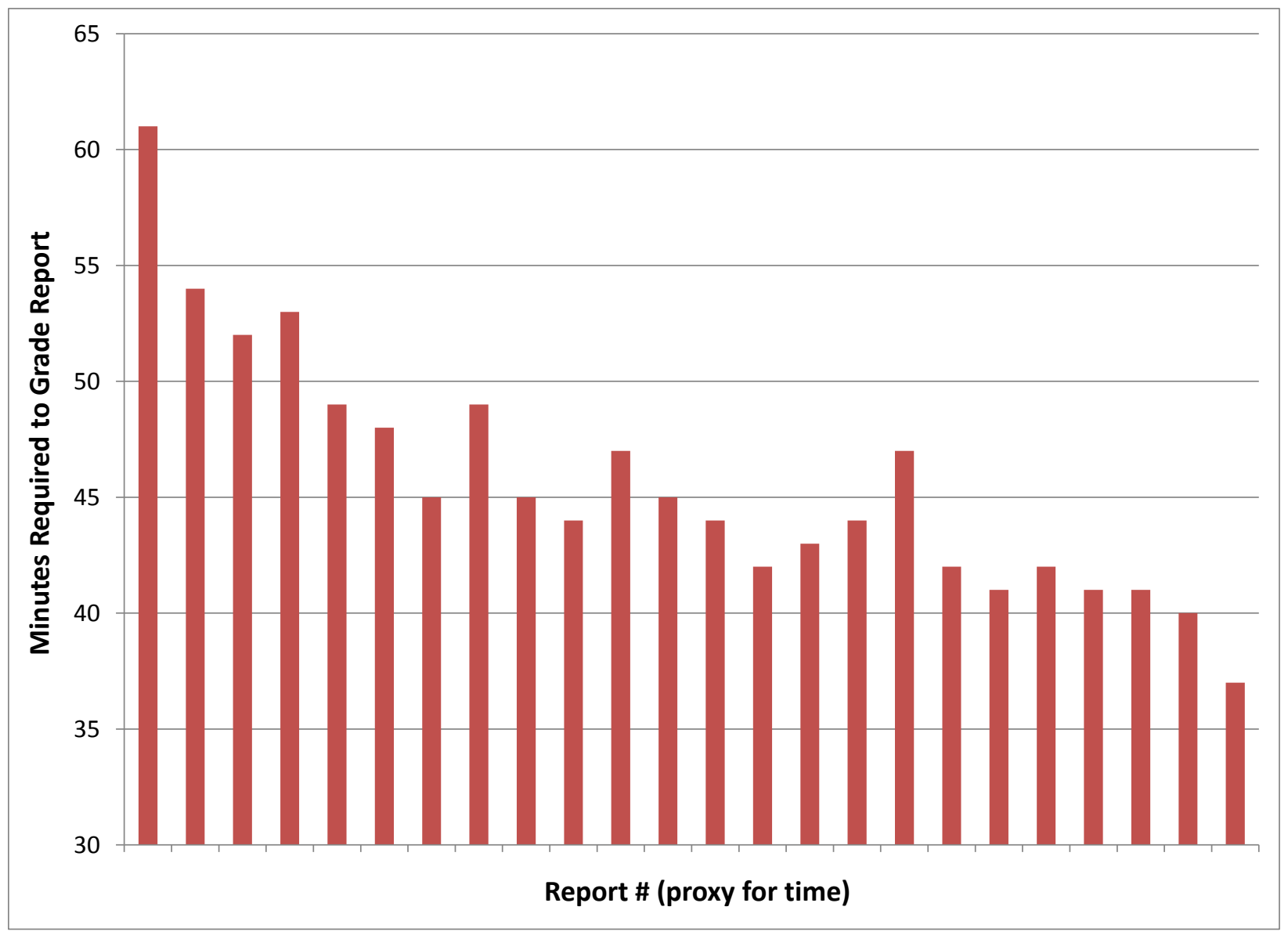

Figure 1. Instructor time spent completing electronic grading of UO laboratory reports.

Two questions regarding the paperless report submission and grading system where asked of students in end-of-semester course evaluations. The first question was "This semester students were given the option to submit and receive grading/evaluation of laboratory reports digitally. Did your group choose to submit laboratory reports digitally? Why?" This question was intended to solicit additional views from students who utilized the paperless option, but also explanation from students who did not use the service. Student responses to this first question are given below:

- "Yes, we submitted reports digitally because it was cheaper and less hassle."

- "We chose to submit them digitally for convenience. It kept us from having to battle [library printing] and spending a small fortune to submit a paper copy of a long lab report."

Anecdotally students valued the convenience of the paperless report submission method. Unfortunately there were no responses from groups who declined to submit reports electronically. 
The second question related to the paperless report system was "Should [the instructor] switch all future CHE 330/331 report submissions and grading to the all-digital format? Why?" which elicited the following student comments:

- "It would save paper and students would be able to make changes at the last minute, but students should have the choice about submitting electronically or not."

- "It was nice to have the option."

- "Keep it the way it is now - encourage online submission but allow paper. It's comforting to have the option if necessary."

These responses show that students appreciate having the option between paperless and hard copy report submissions. With this in mind it is suggested that instructors considering the digital report submission and grading system do not make it compulsory. Additional student feedback is planned to be collected in the Spring 2014 semester and presented at the 2014 ASEE Annual Conference.

Turnitin is a pay service whose license costs approximately $\$ 2000 /$ year for the authors' chemical engineering department. It has been shown that the plagiarism screening service provided as part of the Turnitin license is valuable on its own ${ }^{28}$, and if instructors can complete electronic grading with a similar time commitment as hard copy grading, the paperless grading system may represent a greener alternative to stacks of paper reports. In the opinion of the author paperless submission and grading should be considered as a time-saving measure for instructors already using the plagiarism screening software, but alone it is not worth the licensing fees for the service.

\subsection{Custom experiment preview videos}

Prior to attempting each experiment during the semester, UO students typically visit the laboratory to receive a briefing on equipment operation, data analysis, etc. from the instructor or TA. This approach has a number of issues:

- Each group's preview session lasts 15-20 minutes, which for large classes represents a significant time commitment (up to 20 hours/semester)

- Students often forget information in the interim between the in-person preview and the experiment

- Students "don't know what to ask" during the preview session

- The instructor/TA will give slightly different content in different sessions, perhaps even forgetting to tell one group an important piece of information entirely 
Cicciarelli ${ }^{20}$ describes the use of experiment preview videos which eliminate many of these problems. A critical analysis of the effectiveness of the use of experiment preview videos is presented here.

\subsubsection{Instructor experiences}

Experimental videos were professionally produced with the help of the author's university distance learning division. These videos were produced on-site in the UO laboratory with the instructor speaking, pointing out equipment, etc. just as in a normal in-person preview session. However, adjusting delivery of information to be appropriate for use in a video requires patience and humility for the instructor. Rambling and filler words must be minimized while being sure to communicate all necessary content, which can be a challenge when under the pressure of being on camera. These challenges are manageable, however, and in the author's experience all footage for 8 preview videos (1.5 hours of edited footage) were able to be shot in two full days. Helpful text and bullets describing important equipment, procedures, etc. were able to be added postproduction, as shown in Figure 2. Post-production of videos took the distance learning division $\sim 2$ months to complete. Total cost of recording and producing the videos through this professional avenue was $\$ 5000$. Use of interested students or otherwise amateur production for filming, editing, etc. would represent a much lower $\operatorname{cost}^{20}$.

\subsubsection{Student views and conclusion}

Students' preferences between experiment preview videos and in-person preview sessions were probed in end-of-semester course evaluations by the question "In previous offerings of CHE 330/331, experiment previews were completed in person after quiz/presentation sessions. Do you prefer preview videos or in-person preview sessions? Why?" The following are selected student responses to this question:

- "Videos are easier, and we can watch them multiple times if necessary."

- "I prefer the videos since they allow students to preview the lab at their leisure."

- "Videos were much better. [The instructor] explained things very thoroughly in the video. The only negative is that students may have the tendency to neglect watching the video."

In general, students seemed to prefer the on-demand nature of recorded material rather than inperson previews. However, as indicated by the third student comment, a drawback of video previews is that the impetus is on the student to view the videos on their own time, rather than mandated during class.

Experiment preview videos as applied here represent the greatest cost among the time-saving methods discussed here, but also represent the greatest time savings for UO instructors (20 hours/semester). Anecdotally, students appreciate the on-demand nature of the videos and generally prefer viewing the videos on their own time instead of meeting in person. In the 


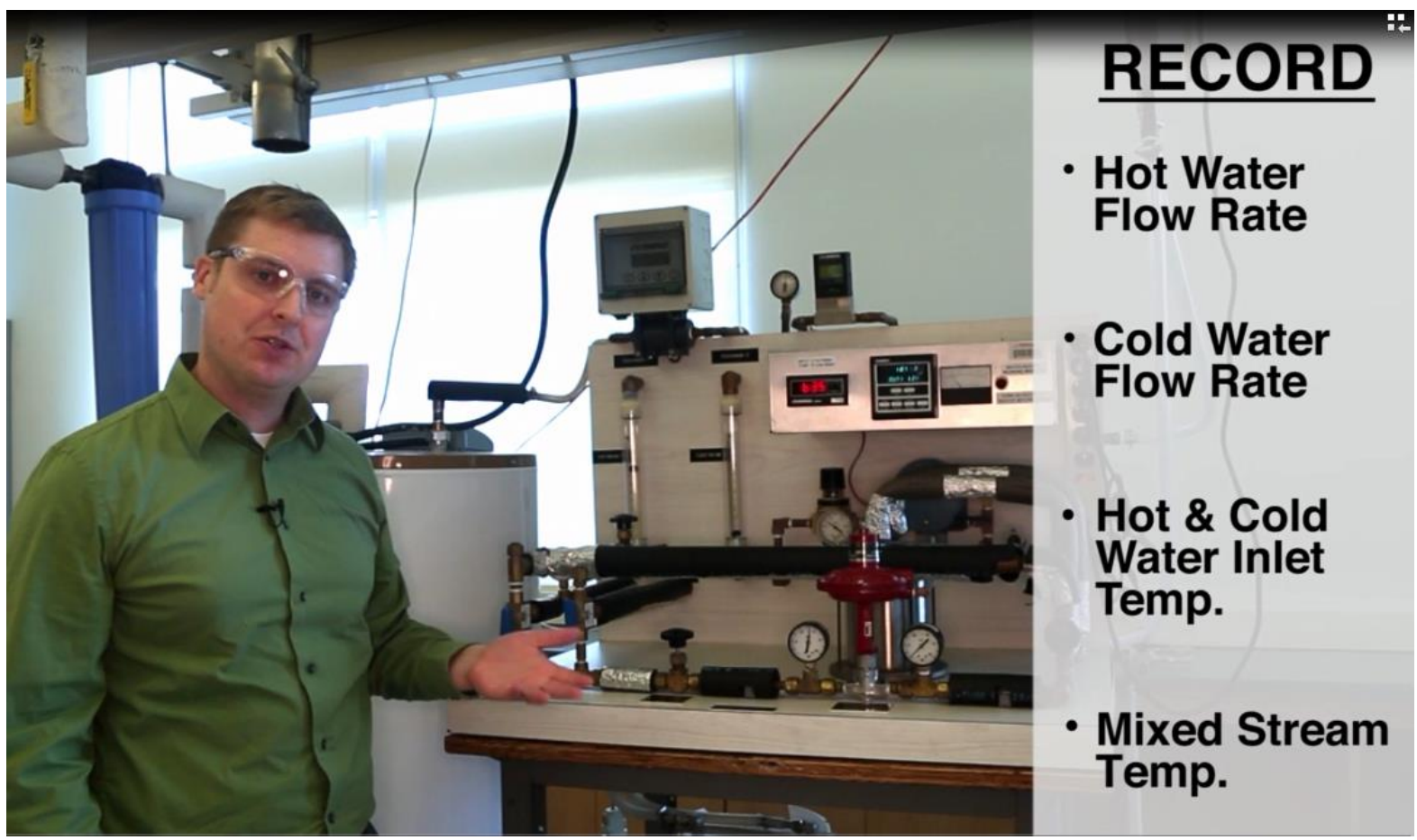

Figure 2. Screen capture of experiment preview videos, showing text prompts useful for students.

author's opinion, if funding is available for experiment preview videos, they are a valuable investment due to significant time savings for the UO instructor.

\subsection{Online lecture content ("Classroom Capture")}

"Classroom Capture" refers to recording audio and video of classroom lectures, then posting this content available online for student review. This feature is offered by many universities under many different names. For the purposes of this article, it is assumed that this technology is already available and represents no cost to the instructor's department.

\subsubsection{Instructor views}

Recording audio and video of lecture content is easy from an instructor perspective, usually requiring only a clip-on microphone and knowledge of how to activate the technology (often from the lectern). However, there are challenges. Student questions are often difficult for the microphone to record, and so any questions must be repeated by the instructor for online viewers. Anecdotally, if this service is used students will expect videos of every lecture, so if a recording of one class session is not available (due to technical problems, etc.), be prepared to field student complaints. When using Classroom Capture technology, attendance seemed to suffer on "getaway" days (e.g. the class session before Spring Break); research on the effect of online lectures on classroom attendance is inconclusive, with studies showing that availability of 
lecture recordings did not have an effect on attendance ${ }^{31-33}$, as well as conflicting studies which show lecture recordings have negative effects on attendance ${ }^{34-36}$.

\subsubsection{Student views and conclusion}

In Fall 2013, the studied courses were not offered in classrooms equipped with the Classroom Capture technology. In order to gauge student interest in use of the technology, end-of-semester peer evaluations included the question "In previous offerings of CHE 330, the Classroom Capture service was used to post video/audio of lecture content online for student review. Unfortunately, this semester CHE 330 was not offered in a room equipped with Classroom Capture technology. Do you wish you had been able to review lecture content online this semester? Why?" Student responses to this question are given below:

- "Yes. I missed two lectures and it would have been great had they been available online."

- "Online lectures are always a plus."

- "Online lecture content would have been useful. It is nice to have the ability to go back and review concepts from the lecture."

Based on these responses alone, students seem to appreciate the availability of online lectures; however, since Classroom Capture was not used in Fall 2013, no conclusions on the efficacy of this technology are offered at this time.

Classroom Capture is being utilized in the studied courses in Spring 2014. The question "As part of CHE 330 video/audio of lecture content was posted online for student review. Did you view the online lecture content? Should the instructor continue offering online lecture content? Why?" will be included on end-of-the-semester course evaluations for the Spring 2014 semester and student responses will be presented at the 2014 ASEE Annual Conference.

\section{Conclusions}

A number of methods to reduce the time commitment for instructors teaching UO courses were evaluated. The use of CATME service for team assignment and collection of peer evaluations was shown to reduce time spent by the instructor by $8-10$ hours over the course of a semester. Since the CATME service is free, it is suggested that all UO instructors consider use of CATME in their courses. Paperless grading reduced paper waste and student stress, but was not found to reduce instructor time spent grading over the tested time period compared to grading hard copy reports. It appears that a "learning curve" exists for using the software and that grading time for the instructor will be reduced after extended use. This possibility will be examined and presented at the 2014 ASEE Conference. Custom videos describing experimental equipment, procedures, etc. represented the greatest one-time monetary cost among tested methods, but was also found to accomplish the greatest reduction in time commitment for the instructor, saving up to 20 hours 
of instructor time over the course of a semester. Data describing student use of the Classroom Capture service will be presented at the 2014 ASEE Annual Conference.

Numerous data was not available at the deadline for submission conference proceedings, but will be available prior to the 2014 ASEE Annual Conference. Additional data will be presented at the 2014 ASEE Annual Conference, specifically:

- Further data to verify "time saved" for each method

- Further data and conclusions describing the "learning curve" for paperless grading

- Student comments from end-of-semester course evaluations for each tested method

Bibliographic Information

1. J. Wildman and W. Bedwell. "Practicing what we preach: teaching teams using validated team science." Small Group Research 44 (4), 381-394 (2013).

2. J. Mathieu, M. Maynard, T. Rapp and L. Gilson. "Team effectiveness 1997-2007: a review of recent advancements and a glimpse into the future." Journal of Management 34, 410-476 (2008).

3. E. Sundstrom, "The challenges of supporting work team effectiveness," in Supporting work team effectiveness. Jossey-Bass, San Francisco, CA (1999).

4. D. Kaufman and R. Felder, "Accounting for individual effort in cooperative learning teams." Journal of Engineering Education 89 (2), 133-140 (2000).

5. L. Kavanagh and C. Crosthwaite, "Triple-objective team mentoring - achieving learning objectives with chemical engineering students." Transactions IChemE Part D, Education for Chemical Engineers 2 68-79 (2007).

6. C. Crosthwaite, I. Cameron, P. Lant and J. Litster, "Balancing curriculum processes and content in a projectcentered curriculum - in pursuit of graduate attributes." Transactions IChemE Part D, Education for Chemical Engineers 1, 29-48 (2006).

7. N. Spinks, N. Silburn and D. Birchall, "Educating engineers for the $21^{\text {st }}$ century: the industry view." Henley Management College, The Royal Academy of Engineering, available at https://www.raeng.org.uk/education/ scet/pdf/henley_report_2011.pdf, last accessed January 2014.

8. World Chemical Engineering Council, "How does chemical engineering education meet the requirements of employment?" available at www.dechema.de/chemengworld_media/Downloads/short_report.pdf, last accessed January 2014.

9. J. Moy, "The impact of generic competencies on workplace performance." Review of Research Monograph Series, available at National Centre for Vocational Education Research, ISBN 0873975278 (1999).

10. H. Foyle, in Interactive learning in the higher education classroom. National Education Association, Ann Arbor, MI (1995).

11. R. Drake, G. Goldsmith and R. Strachan, "A novel approach to teaching teamwork." Teaching in Higher Education 11 (1), 33-46 (2006).

12. D. Jones, "Team learning approach in education," Journal of Quality and Participation 19 (1), 80-87 (1996)

13. K. Smith, "Cooperative learning: making 'groupwork' work." New Directions for Teaching and Learning 67, 71-82 (1996).

14. R. Felder and R. Brent, "Effective strategies for cooperative learning." Journal of Cooperation \& Collaboration in College Teaching 10 (2), 69-75 (2001).

15. S. Chandra, "Role and effectiveness of practical laboratory courses in technical education." AEESEAP Conference Proceedings, 225-230 (1991).

16. B. Young, H. Yarranton, C. Bellehumeur and W. Svrcek, "An experimental design approach to chemical engineering unit operations laboratories." Transactions IChemE Part D, Education for Chemical Engineers 1, 16-22 (2006). 
17. M. Ohland, M. Loughry, D. Woehr, L. Bullard, R. Felder, C. Finelli, R. Layton, H. Pomeranz, and D. Schmucker, "The Comprehensive Assessment of Team Member Effectiveness: Development of a Behaviorally Anchored Rating Scale for Self and Peer Evaluation." Academy of Management Learning \& Education 11 (4), 609-630 (2012).

18. M. Ohland, H. Pomeranz and H. Feinstein, "The comprehensive assessment of team member effectiveness: a new peer evaluation instrument." ASEE Annual Conference Proceedings \#2006-1286 (2006).

19. R. Layton, M. Ohland and H. Pomeranz, "Software for student team formation and peer evaluation: CATME incorporates team-maker." ASEE Annual Conference Proceedings \#2007-1565 (2007).

20. B. Cicciarelli, "Use of pre-recorded video demonstrations in laboratory courses." Chemical Engineering Education 47 (2), 133-136 (2013).

21. The Foundation Coalition, "Forming student engineering teams." available at www.foundationcoalition.org/ teams, last accessed January 2014.

22. S. Feichtner and E. Davis, "Why some groups fail: a survey of students' experiences with learning groups." Organizational Behavior Teaching Review 9, 58-71 (1984).

23. J. Brickell, D. Porter, M. Reynolds and R. Cosgrave, “Assigning students to groups for engineering design projects: a comparison of five methods." Journal of Engineering Education 7, 259-262 (1994).

24. C. Heldt, "Peer evaluation in chemical engineering capstone design via wikis." Chemical Engineering Education 46 (3) 189-195 (2012).

25. M. Ohland, R. Layton, M. Loughry and A. Yubasz, "Effects of behavioral anchors on peer evaluation reliability." Journal of Engineering Education 94 (3), 319-326 (2005).

26. E. Rojas, "Use of web-based tools to enhance collaborative learning." Journal of Engineering Education 91 (1), 89-95 (2002).

27. Turnitin.com, "Customers - College and University.” Available at http://www.turnitin.com/en_us/customers/ college-and-university, last accessed January 2014.

28. M. Cooper, L. Bullard, S. Peretti and D. Ollis, "Application of plagiarism screening software in the chemical engineering curriculum.” ASEE Annual Conference Proceedings \#2012-3315 (2012).

29. W. Conner, K. Hammond and R. Laurence, "A moveable feast - a progressive approach to the unit operations laboratory." Chemical Engineering Education 45 (3) 193-201 (2011).

30. K. Zickuhr, "Tablet Ownership 2013." available at http://www.pewinternet.org/Reports/2013/TabletOwnership-2013/Findings.aspx, last accessed January 2014.

31. J. Brotherton and G. Abowd, "Lessons learned from eClass: assessing automated capture and access in the classroom.” ACM Transactions on Computer-Human Interaction 11 (2), 121-155 (2004).

32. O. McGarr, "A review of podcasting in higher education: its influence on the traditional lecture." Australasian Journal of Educational Technology 25 (3) 309-321 (2009).

33. A. Nast, G. Schäfer-Hesterberg, H. Zielke, W. Sterry and B. Rzany, “Online lectures for students in dermatology: a replacement for traditional teaching or a valuable addition?" Journal of the European Academy of Dermatology and Venereology 23, 1039-1043 (2009).

34. R. Owston, D. Lupshenyuk and H. Wideman, "Lecture capture in large undergraduate classes: student perceptions and academic performance." Internet and Higher Education 14 (4) 262-268 (2011).

35. K. Woo, M. Gosper, M. McNeill, G. Preston, D. Green and R. Phillips, "Web-based lecture technologies: blurring the boundaries between face-to-face and distance learning." ALT-J 16 (2), 81-93 (2008).

36. T. Traphagan, J. Vucsera and K. Kishi, "Impact of class lecture web casting on attendance and learning." Educational Technology Research and Development 58 (1), 19-37. (2010). 